\title{
A Rare Case of Endometrial Adenocarcinoma with Renal Clear Cell Carcinoma
}

\author{
${ }^{1}$ Prashanthi Damodharan, ${ }^{2}$ Usha Vishwanath, ${ }^{3}$ Priyanka Mehta, ${ }^{4} \mathrm{~S}$ Gouthaman, ${ }^{5} \mathrm{~K}$ Sriram
}

\begin{abstract}
Patients diagnosed with cancer have a lifetime risk of developing another de novo malignancy. The incidence of two primaries in the same patient is an extremely rare condition, and there are no specific guidelines for management. There are less than ten reported cases of coincidental renal cell cancer in a patient with endometrial cancer. In a woman who presented with postmenopausal bleeding with endometrial carcinoma, an incidental primary renal cell carcinoma was diagnosed and treated successfully by a multidisciplinary team of gynecologists, oncosurgeon, urologist, radiologist, pathologist, and a medical oncologist. We are reporting this case due to its rarity and clinical interest. A high index of clinical suspicion would go a long way in the management of such tumors.
\end{abstract}

Keywords: Endometrial adenocarcinoma, Leptin, Peroxisome proliferators activators receptor gamma, Renal clear cell carcinoma.

How to cite this article: Damodharan P, Vishwanath U, Mehta P, Gouthaman S, Sriram K. A Rare Case of Endometrial Adenocarcinoma with Renal Clear Cell Carcinoma. J South Asian Feder Menopause Soc 2018;6(2):135-138.

Source of support: Nil

Conflict of interest: None

Date of received: 10 January 2018

Date of acceptance: 27 January 2018

Date of publication: July 2018

\section{INTRODUCTION}

The presence of multiple primary malignant neoplasms has been well documented in the literature, but its occurrence in a single patient is relatively rare. The incidence is less than $4 \%{ }^{1}$ They can be synchronous or

\footnotetext{
${ }^{1}$ Postgraduate Student, ${ }^{2,5}$ Professor, ${ }^{3,4}$ Associate Professor

${ }^{1-3}$ Department of Obstetrics and Gynecology, Sri Ramachandra Medical College and Research Institute, Chennai, Tamil Nadu, India

${ }^{4}$ Department of Surgical Oncology, Sri Ramachandra Medical College and Research Institute, Chennai, Tamil Nadu, India

${ }^{5}$ Department of Urology, Sri Ramachandra Medical College and Research Institute, Chennai, Tamil Nadu, India

Corresponding Author: Prashanthi Damodharan, Postgraduate Student, Department of Obstetrics and Gynecology, Sri Ramachandra Medical College and Research Institute, Chennai, Tamil Nadu, India, e-mail: dprash29@gmail.com
}

metachronous in nature. Development of more sophisticated diagnostic tools has made possible the detection of synchronous occult malignancies. ${ }^{2}$ The newer treatment modalities have led to an increase in the lifespan of patients who have cancer thereby possibly exposing them to a greater risk of developing subsequent malignancies. Our case of a synchronous double primary incidental renal clear cell carcinoma (RCC) with endometrial adenocarcinoma is very rare, with approximately only less than ten cases being reported earlier to the best of our knowledge.

\section{CASE HISTORY}

A 52-year-old postmenopausal lady para 1 live 1 abortion 2 was referred to our tertiary care center in July 2015 with intermittent postmenopausal bleeding. She was started on progesterone therapy outside, which did not relieve her symptoms. She had no previous history of contraceptive pill usage nor a positive family history of malignancies. She had no bowel and bladder disturbances. She was not a diabetic or hypertensive.

On examination, she was anemic with a hemoglobin of $9 \mathrm{~g} / \mathrm{dL}$ with a body mass index of $30.5 \mathrm{~kg} / \mathrm{m}^{2}$. Her blood pressure was $120 / 70 \mathrm{~mm} \mathrm{Hg}$. There was no mass palpable on abdominal and pelvic examination. Pap smear was found to be negative for intraepithelial malignancy.

Transvaginal ultrasound revealed a bulky uterus measuring $8.3 \times 4.9 \mathrm{~cm}$, with inhomogeneous myometrial echotexture (Fig. 1). Endometrial thickness was $22 \mathrm{~mm}$. Irregular and heterogeneous mass involving the endocervical canal, invasion into myometrium more than 50

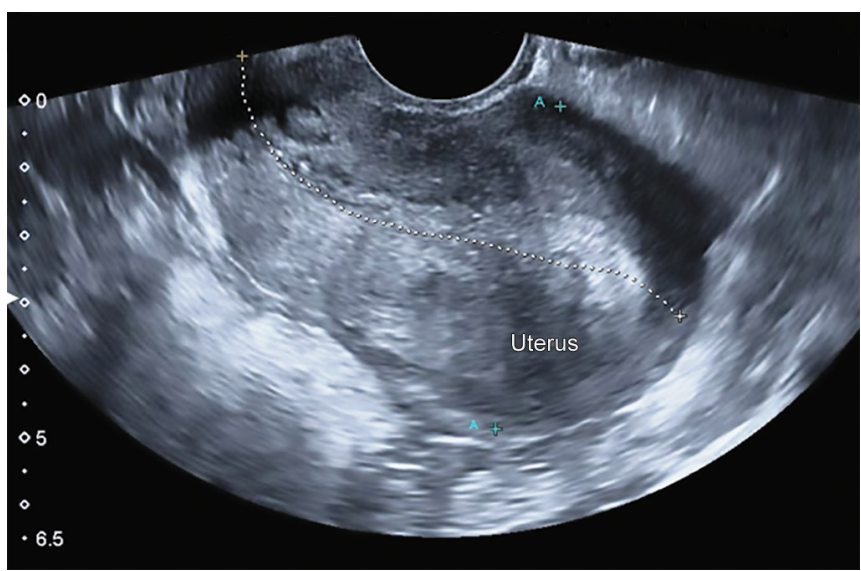

Fig. 1: Transvaginal USG showing bulky postmenopausal uterus with inhomogeneous myometrial echotexture 


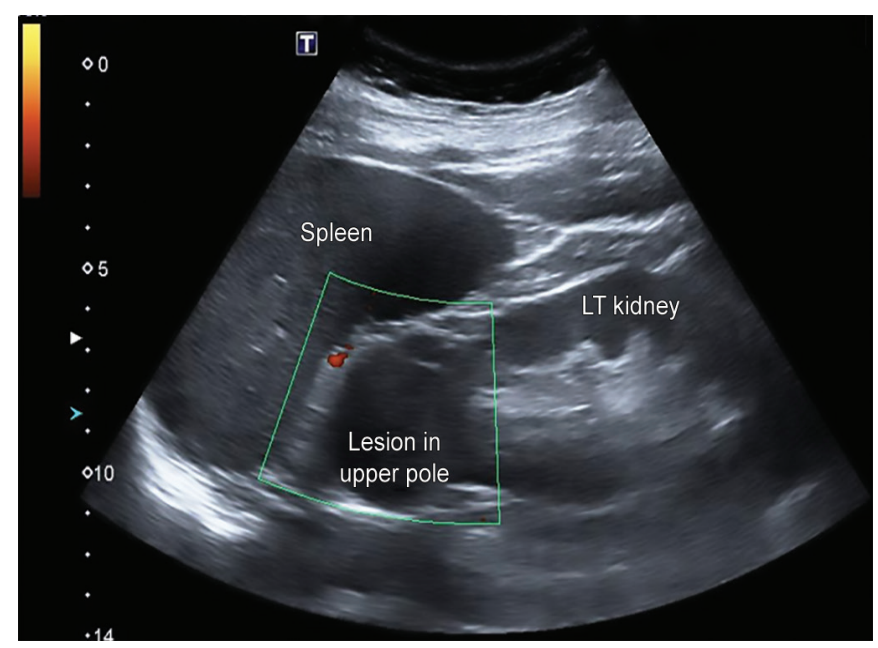

Fig. 2: Transabdominal USG showing a heterogeneously hypoechoic lesion in the upper pole of the left kidney

percent in fundus (posteriorly) was seen. Transabdominal ultrasound shows a heterogeneously hypoechoic lesion in the upper pole of the left kidney which shows no vascularity on power Doppler (Fig. 2). Endometrial biopsy was reported as complex hyperplasia with atypia. On further imaging, MRI showed an ill-defined, poorly circumscribed lesion of $2 \mathrm{~cm}$ in the endometrium invading the myometrium and extending into the cervix (Fig. 3). Bilateral subcentimeter iliac and obturator nodes were noted. A complex heterogeneous lesion of size $4.3 \times 4.1$ $\mathrm{cm}$ was seen arising from the superior pole of the left kidney (Figs 4 and 5).

She underwent total abdominal hysterectomy with bilateral salpingo-oophorectomy with bilateral pelvic lymphadenectomy. Intraoperative findings were uterus of 10 weeks size, bilateral tubes and ovaries normal. On cut section of the specimen, a $3 \times 3 \mathrm{~cm}$ polypoidal friable mass occupying less than half of myometrium was evident (Figs 6 and 7). No growth in the cervix. Frozen section was reported as endometrial adenocarcinoma involving

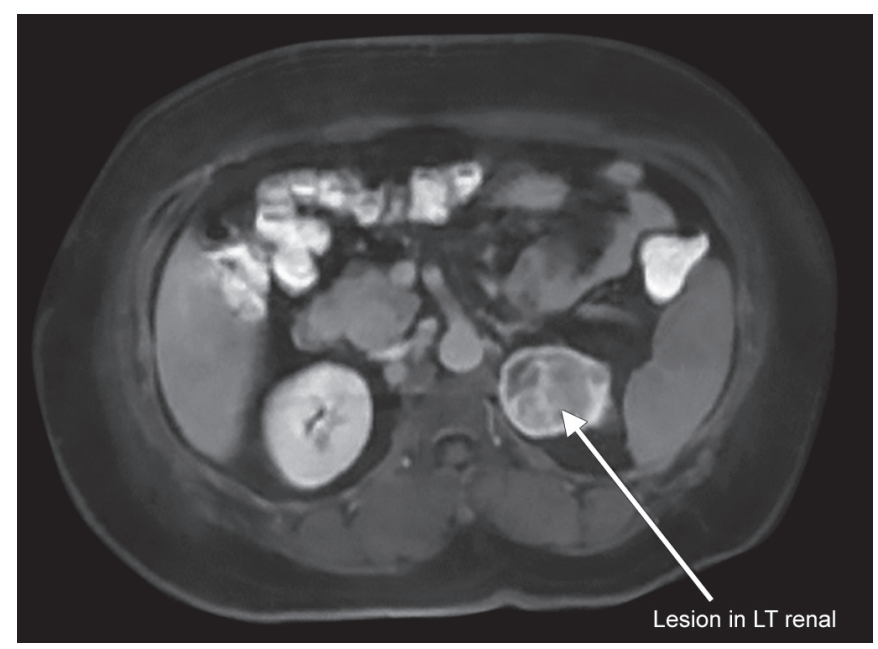

Fig. 4: MRI T1W showing a hypointense heterogeneous mass lesion arising from the superior pole of the left kidney

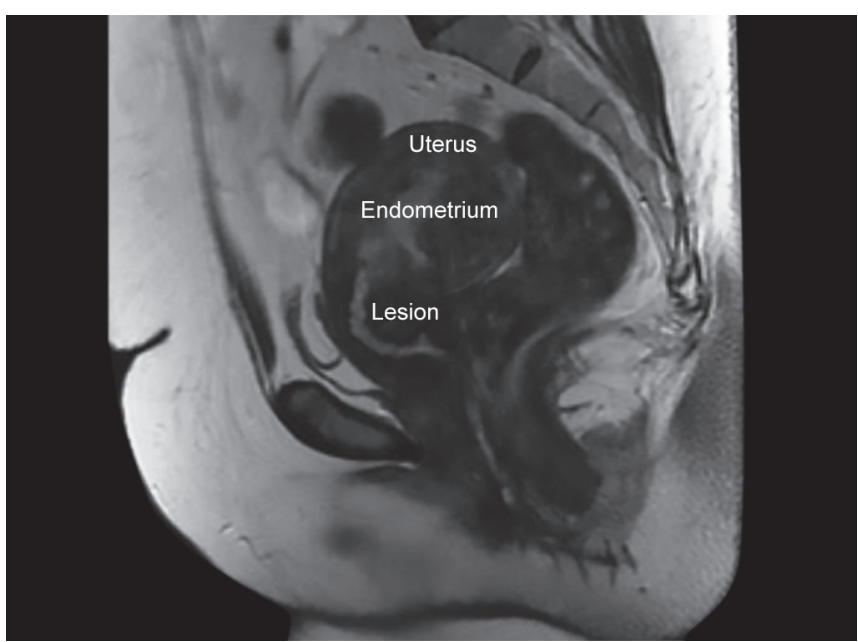

Fig. 3: MRI T1W sagittal section showing ill-defined hypointense lesion arising from endometrium, invading into the myometrium and extending into the cervix

less than $50 \%$ myometrium and that of the intraoperative tru-cut biopsy of the renal mass was reported as possibly clear cell carcinoma. Hence left radical nephrectomy was done with the help of the urologist during the same sitting (Fig. 8). Postoperatively patient recovered well. Suture removal was done on the 10th postoperative day.

Histopathology of the uterine mass was endometrioid adenocarcinoma of the endometrium, FIGO stage 2(Fig. 9). Pelvic nodes were negative. Histology of the renal mass was confirmed to be another primary clear cell carcinoma (Fig. 10).

On follow-up, PET CT was done which showed no metabolically active disease elsewhere.

\section{DISCUSSION}

The development of multiple primary malignancies may be due to genetic events or environmental risk factors. The criteria used to diagnose multiple primary cancers was described by Warren and Gates ${ }^{1}$ (Box 1).

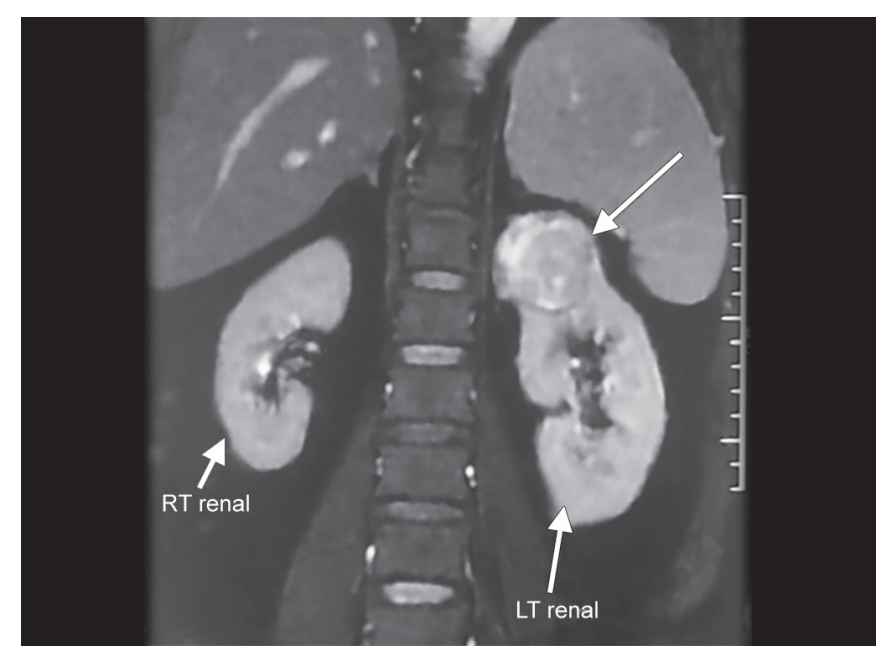

Fig. 5: MRIT1W sequence coronal image showing a complex heterogeneous lesion arising from the upper pole of left kidney 


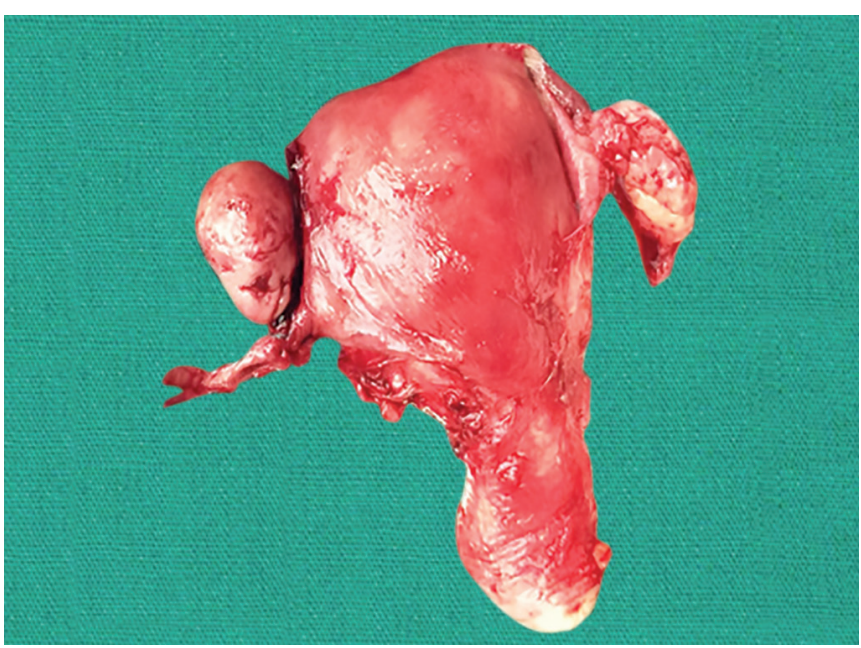

Fig. 6: Gross specimen of the uterus with bilateral tubes and ovaries

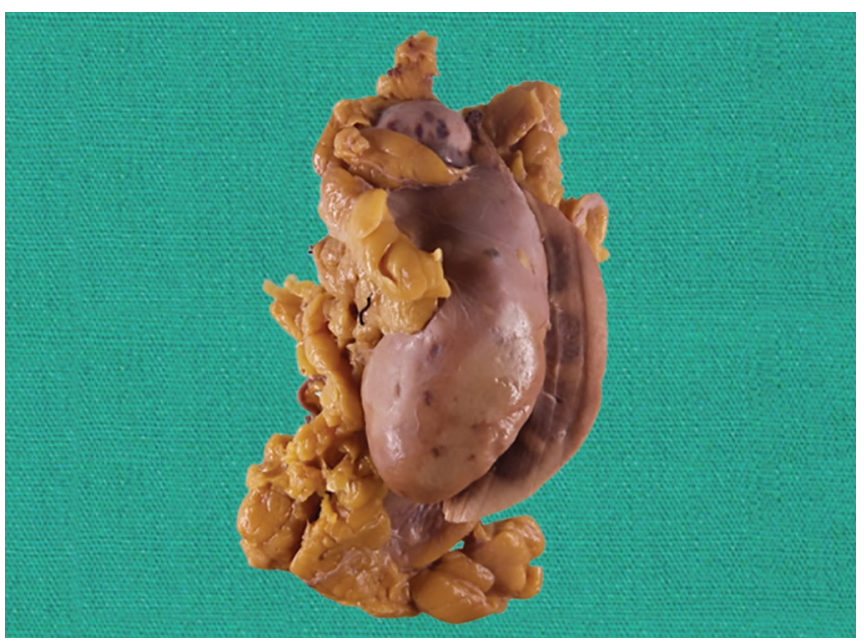

Fig. 8: Left radical nephrectomy specimen with cancerous growth in the upper pole

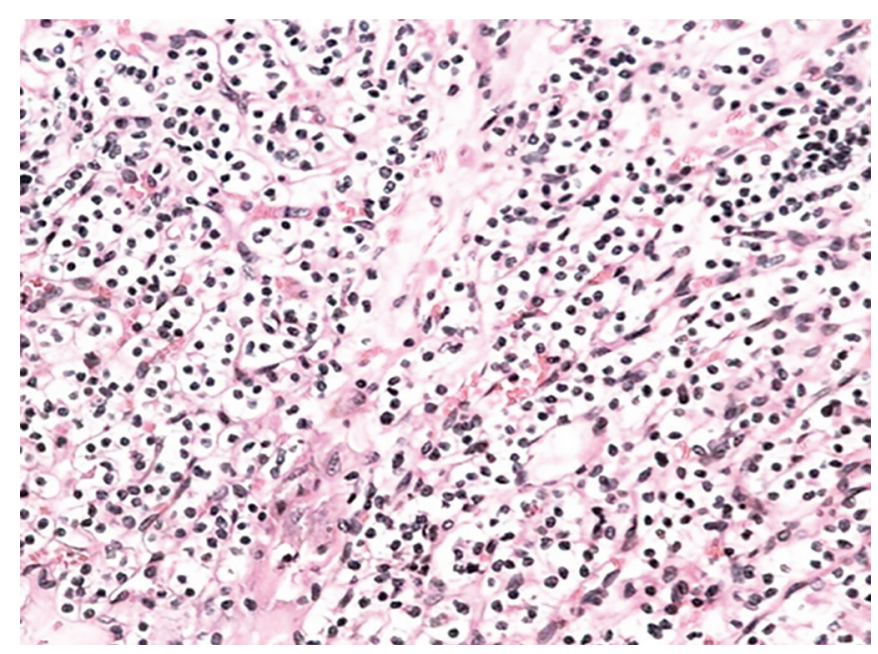

Fig. 10: Histopathology slide showing renal clear cell carcinoma

Synchronous cancers are second tumors which occur simultaneously or within 6 months after the first malignancy, while metachronous are secondary cancers that develop after 6 months from the first malignancy. Multiple primary malignancies are classified into four types: (1) multicentric, if they arise in the same organ

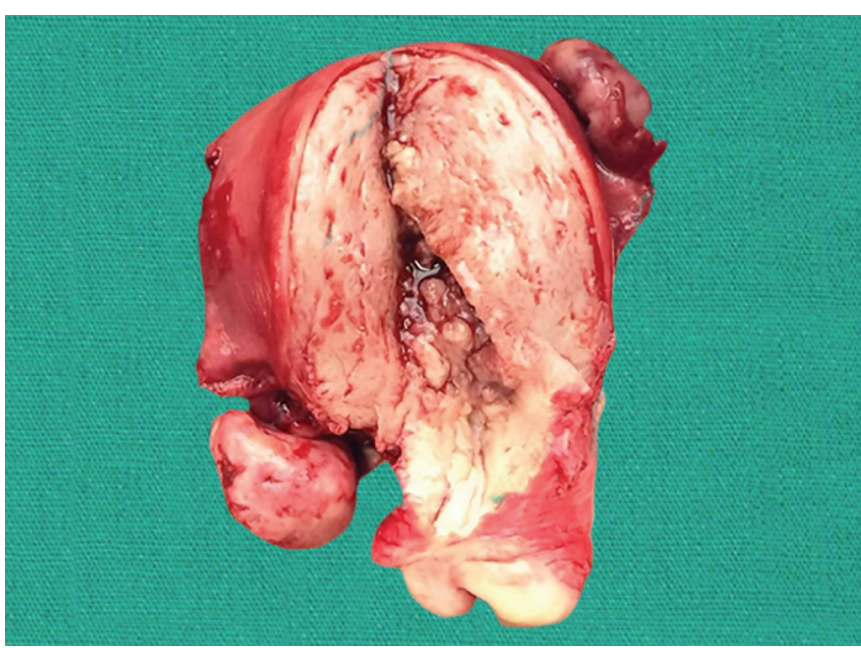

Fig. 7: Cut section of the uterus showing polypoidal growth in the endometrium

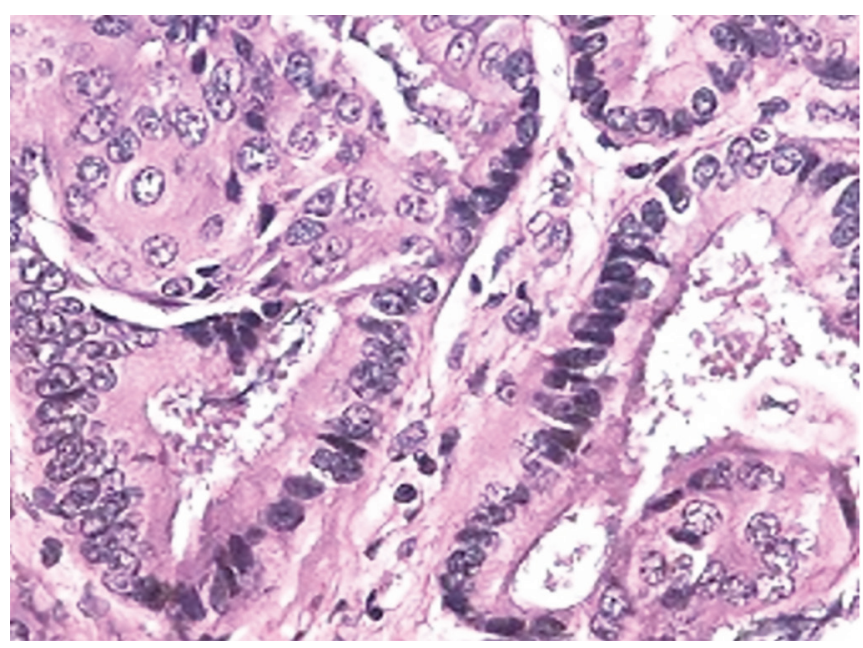

Fig. 9: Histopathology slide showing endometrioid adenocarcinoma of the endometrium

Box 1: Warren and Gates criteria

- Each tumor must be malignancy confirmed by histology

- Each must be geographically separate and distinct

- The possibility of one being the metastasis of the other must be excluded.

or tissue, (2) systemic, if they arise on anatomically or functionally allied organs of the same system (colon and rectum cancers), (3) paired organs, as in the breasts, and (4) random, if they occur as a co-incidental or accidental association in unrelated sites. ${ }^{3}$ Our synchronous, random second tumor was diagnosed incidentally on preoperative imaging. A detailed evaluation is necessary to differentiate between a second primary and metastatic disease. Little is known about the etiology of endometrial and renal cell cancer. Risk factors include hyperestrogenic states, obesity, and genetic predisposition. De Silverio et al. reported high plasma estrogen levels in one out of his four cases of renal cell carcinoma with endometrial cancer which proves the causal association. ${ }^{4}$ Bhat et al. found the presence of estrogen receptors in hamster and mouse kidneys. ${ }^{5}$ Obesity associated with high leptin levels 
(cytokine derived from adipocyte) is a major cause in postmenopausal women with endometrial cancer. ${ }^{6}$ High leptin levels are an independent risk factor of endometrial carcinoma. ${ }^{7}$ Leptin promotes endometrial proliferation and invasiveness by inhibiting endometrial carcinoma cell apoptosis. ${ }^{8}$ Smith et al. studied that peroxisome proliferators activators receptor gamma (PPARG), that regulates cell growth and differentiation, serves as a susceptibility gene for obesity-related cancers like endometrium, ovary, kidney, cervix, and prostate. ${ }^{9}$

\section{CONCLUSION}

Most of the synchronous tumors are incidentally diagnosed during staging evaluation of the primary tumor. When multiple tumors are pathologically confirmed at the time of the presentation itself, each tumor should be evaluated and staged as independent tumors. They should be treated aggressively with the curative intent depending on the stage of each disease to achieve maximum therapeutic benefit. If surgery is needed for both the tumors, it can be done in a single stage with low rates of morbidity and mortality ${ }^{10}$ as was done in our case.

\section{REFERENCES}

1. Warren S, Gates O. Multiple primary malignant tumors: A survey of the literature and a statistical study. Am J Cancer 1932;16:1358-1414.
2. Kim JW, Han JW, et al. Synchronous double primary malignant tumor of the gallbladder and liver: a case report. World J Surg Oncol 2011;9:84.

3. Moertel CG. Multiple primary malignant neoplasms: historical perspectives. Cancer 1977;40(4 Suppl):1786-1792. PMID No 332330

4. Di Silverio F, Sciarra A, et al. Multiple primary tumors: 17 cases of renal-cell carcinoma associated with primary tumors involving different steroid hormone target tissues. World J Urol 1997;15(3):203-209. PMID 9228728.

5. Bhat HK, Hacker HJ, et al. Localization of estrogen receptors in interstitial cells of hamster kidney and in estradiol-induced renal tumors as evidence of the mesenchymal origin of this neoplasm.Cancer Res 1993;53(22):5447-5451.

6. Cymbaluk A, Chudecka-Glaz A, et al. Leptin levels in serum depending on Body Mass Index in patients with endometrial hyperplasia and cancer. Eur J ObstetGynecolReprod Biol 2008 Jan;136(1):74-77.

7. Wang $\mathrm{PP}, \mathrm{He} \mathrm{XY}$, et al. High leptin level is an independent risk factor of endometrial cancer: a meta-analysis.CellPhysiolBiochem. 2014;34(5):1477-84. Epub 2014 Oct 8. PMID:25322729

8. Zhou X, Li H, et al. Leptin Inhibits the Apoptosis of Endometrial Carcinoma Cells Through Activation of the Nuclear Factor кB-inducing Kinase/IкB Kinase Pathway. Int J Gynecol Cancer. 2015 Jun;25(5):770-778. PMID: 25811593

9. Smith WM, Zhou XP, et al. Opposite association of two PPARG variants with cancer: overrepresentation of $\mathrm{H} 449 \mathrm{H}$ in endometrial carcinoma cases and underrepresentation of P12A in renal cell carcinoma cases.Hum Genet 2001;109(2):146-51. PMID 11511919

10. Suzuki S, Nishimaki T, et al. Outcomes of simultaneous resection of synchronous esophageal and extra esophageal carcinomas. J Am CollSurg 2002;195(1):23-29. PMID 12113541. 